\title{
Efficacy of Bacteriophage Therapy in Experimental Sepsis and Meningitis Caused by a Clone O25b:H4-ST131 Escherichia coli Strain Producing CTX-M-15
}

\author{
Flavie Pouillot, ${ }^{\mathrm{b}}$ Maryline Chomton, ${ }^{\mathrm{a}}$ Hélène Blois, ${ }^{\mathrm{b}}$ Celine Courroux, ${ }^{\mathrm{a}}$ Julien Noelig, ${ }^{\mathrm{b}}$ Philippe Bidet, ${ }^{\mathrm{a}}$ Edouard Bingen, ${ }^{\mathrm{a}}$ \\ and Stéphane Bonacorsi ${ }^{\mathrm{a}}$ \\ Université Paris Diderot, Sorbonne Paris Cité, Equipe d'accueil EA3105, and AP-HP, Hôpital Robert Debré, Paris, France, and Pherecydes Pharma, Romainville, France ${ }^{\mathrm{b}}$
}

\begin{abstract}
We evaluated phage therapy in experimental infections due to S242, a fatal neonatal meningitis Escherichia coli strain belonging to the worldwide-distributed O25b:H4-ST131 clone that produces extended-spectrum beta-lactamase CTX-M-15. A lytic phage, $\mathrm{EC} 200^{\mathrm{PP}}$, active against S242, was isolated from environmental water. After determining in vitro and ex vivo stabilities and pharmacokinetic properties of EC200 ${ }^{\mathrm{PP}}$ in rat pups, we assessed the therapeutic efficacy of a single dose of $10^{8} \mathrm{PFU}$ using models of sepsis and meningitis in which fatality was $100 \%$. EC200 ${ }^{\mathrm{PP}}$ was partially neutralized by human serum. In contrast to the high concentration of phage in the spleen and the kidney, low titers in urine and the central nervous system were observed. Nevertheless, in the sepsis model, EC200 ${ }^{\mathrm{PP}}$ administered $7 \mathrm{~h}$ or $24 \mathrm{~h}$ postinfection resulted in $100 \%$ and $50 \%$ pup survival, respectively. In the meningitis model, EC200 ${ }^{\mathrm{PP}}$ administered $1 \mathrm{~h}$ or $7 \mathrm{~h}$ postinfection rescued $100 \%$ of the animals. The most delayed treatments were associated with the selection of phage-resistant S242 mutants. However, a representative mutant was highly sensitive to killing serum activity and avirulent in an animal model. $\mathrm{EC} 200^{\mathrm{PP}}$ is a potential therapeutic agent for sepsis and meningitis caused by the widespread $E$. coli $\mathrm{O} 25: \mathrm{H} 4-\mathrm{ST} 131$ multidrug-resistant clone.
\end{abstract}

E cherichia coli is the leading bacterial pathogen responsible for extraintestinal infections, including urinary tract infections, bacteremia, and meningitis. Neonatal meningitis is one of the most severe E. coli infections, killing up to one-quarter of those infected (18). The future prognosis of this disease may be worsened by the increasing incidence of multidrug-resistant strains of E. coli, especially those producing extended-spectrum beta-lactamases (ESBL) such as CTX-M-type enzymes. Until 2005, no E. coli meningitis strain resistant to expanded-spectrum cephalosporins had been reported in France (20). In 2008, we described the first fatal neonatal meningitis due to a CTX-M-15-producing E. coli strain resistant to fluoroquinolones (5). We along with others have since reported several cases of ESBL-producing E. coli meningitis $(16,34)$, with carbapenem being the sole therapeutic alternative. The recent finding of a worldwide dissemination in Enterobacteriaceae of the NDM-1 enzyme which hydrolyzes carbapenem may soon lead to cases with no therapeutic issue (3).

An alternative approach, phage therapy, has the potential to circumvent antibiotic resistance by lysing pathogenic bacteria. Though used for decades in Eastern Europe, successful phage therapy has been demonstrated only recently in experimental models $(8,11,15,27,36,40,43,44)$. Because bacteriophage replicate at infection sites, efficacy may require just a single dose (23, 40). Although phage-resistant mutants may be selected during treatment, they are often less virulent $(8,23)$ and thus do not usually compromise treatment. In general, the specificity of phage infection ensures that the bulk of the body's microflora is unaffected $(6,12)$.

Although experimental phage therapy against E. coli infections has been previously reported, there are, to our knowledge, no data on phage therapy for E. coli meningitis. The aim of this study was to isolate a lytic phage of a CTX-M-15-producing E. coli strain belonging to the widespread, multidrug-resistant O25b:H4-
ST131 clone to determine its pharmacokinetic properties and to assess its efficacy in neonatal sepsis and meningitis rat models.

\section{MATERIALS AND METHODS}

Bacterial strains. E. coli S242, a ciprofloxacin resistant, CTX-M-15 ESBLproducing strain, was isolated from a neonate with fatal meningitis (5). This strain is capsular antigen $\mathrm{K} 1$ negative and belongs to the $\mathrm{B} 2$ phylogenetic group. We further characterized $\mathrm{S} 242$ by determining its serotype, sequence type (ST), and virulence genotype, as described previously (2, 14,29 ), in order to determine whether S242 belongs to the clone O25b: H4-ST131 that produces CTX-M-15.

Sixty-three E. coli strains representative of the E. coli reference (ECOR) collection and E. coli meningitis strains of different serotypes and sequence types previously described (2), as well as reference strains and strain TN03, representative of the O25b:H4-CTX-M-15-ST131 clone (14, 35), were used for phage host range determination (Table 1).

Phage isolation, preparation, and characterization. S242 was used for isolating and enriching virulent bacteriophage from the environment (mainly sewage water from different areas of France). Environmental samples and cells from an overnight culture of E. coli S242 in Luria Bertani (LB) medium were mixed and incubated at $37^{\circ} \mathrm{C}$ for $24 \mathrm{~h}$ with shaking to enrich for E. coli-specific bacteriophage. After addition of chloroform, debris and unlysed cells were removed by centrifugation at $11,000 \times g$ for $5 \mathrm{~min}$, followed by passage of the supernatant through a $0.2-\mu \mathrm{m}$-pore-size

Received 11 December 2011 Returned for modification 4 March 2012 Accepted 1 April 2012

Published ahead of print 9 April 2012

Address correspondence to Stéphane Bonacorsi, stephane.bonacorsi @rdb.aphp.fr

F. Pouillot and M. Chomton contributed equally to this article.

Supplemental material for this article may be found at http://aac.asm.org/. Copyright @ 2012, American Society for Microbiology. All Rights Reserved. doi:10.1128/AAC.06330-11 
TABLE 1 Host range determination of phage $\mathrm{EC} 200^{\mathrm{PP} a}$

\begin{tabular}{|c|c|c|c|}
\hline Bacterial strain & $\begin{array}{l}\text { Phylogenetic } \\
\text { group }\end{array}$ & Serotype & EC200 ${ }^{\mathrm{PP}}$ activity $^{b}$ \\
\hline ECOR1 & A & ON:HN & \\
\hline ECOR2 & A & ON:H32 & \\
\hline ECOR5 & A & O79:NM & \\
\hline ECOR10 & A & O6:H10 & \\
\hline ECOR4 & A & ON:HN & \\
\hline ECOR6 & A & ON:NM & \\
\hline ECOR13 & A & ON:HN & \\
\hline ECOR24 & A & O15:NM & \\
\hline ECOR15 & A & O25:NM & \\
\hline ECOR28 & B1 & O104:NM & \\
\hline ECOR71 & B1 & O78:NM & \\
\hline ECOR72 & B1 & O144:H8 & \\
\hline ECOR54 & B2 & $\mathrm{O} 25: \mathrm{H} 1$ & \\
\hline ECOR55 & B2 & O25:H1 & + \\
\hline ECOR56 & B2 & O6:H1 & \\
\hline ECOR59 & B2 & $\mathrm{O} 4: \mathrm{H} 40$ & \\
\hline ECOR60 & B2 & O4:HN & \\
\hline ECOR62 & B21 & $\mathrm{O} 2: \mathrm{NM}$ & \\
\hline ECOR64 & B2 & O75:NM & \\
\hline ECOR35 & $\mathrm{D}$ & O1:NM & \\
\hline ECOR38 & $\mathrm{D}$ & O7:NM & \\
\hline ECOR40 & $\mathrm{D}$ & O7:NM & \\
\hline ECOR46 & $\mathrm{D}$ & O1:H6 & \\
\hline ECOR48 & $\mathrm{D}$ & ON:HN & \\
\hline ECOR50 & $\mathrm{D}$ & $\mathrm{O} 2: \mathrm{HN}$ & + \\
\hline CFT073 & B2 & O6:K2:H1 & \\
\hline J96 & B2 & O4:K6 & \\
\hline 536 & B2 & O6:K15:H31 & \\
\hline TN03 & B2 & O25b:H4 & + \\
\hline S5 & B2 & O18:H7 & \\
\hline S11 & B2 & $\mathrm{O} 35: \mathrm{H} 4$ & \\
\hline S12 & B2 & O18:H7 & \\
\hline S13 & $\mathrm{D}$ & $\mathrm{O} 7: \mathrm{H} 4$ & \\
\hline S15 & B2 & O83:H- & \\
\hline S22 & B2 & O6:H1 & + \\
\hline S25 & B2 & O18:H7 & \\
\hline S39 & $\mathrm{D}$ & O7:H- & \\
\hline S41 & A & $\mathrm{O} 2: \mathrm{H}-$ & \\
\hline S43 & B2 & O6:H1 & \\
\hline S49 & B2 & $\mathrm{O} 25: \mathrm{H}-$ & + \\
\hline S51 & B1 & O128:H2 & \\
\hline S55 & A & O16:H- & \\
\hline S63 & $\mathrm{D}$ & O1:H7 & \\
\hline S69 & B2 & O18:H7 & \\
\hline S88 & B2 & $\mathrm{O} 45: \mathrm{H} 7$ & \\
\hline S97 & B2 & O8:H6 & \\
\hline S102 & $\mathrm{D}$ & O166:H15 & \\
\hline S104 & B2 & O1:H7 & \\
\hline S105 & B2 & O14:H7 & \\
\hline S106 & B2 & O16:H6 & \\
\hline S113 & A & $\mathrm{O} 12: \mathrm{H}-$ & \\
\hline S120 & B1 & $\mathrm{O} 23: \mathrm{H}-$ & \\
\hline S123 & A & O78:H4 & \\
\hline S124 & B2 & O1:H7 & \\
\hline S130 & B2 & O83:H5 & + \\
\hline S133 & B2 & O18:H7 & \\
\hline S138 & A & O21:H4 & \\
\hline S149 & B2 & O83:H1 & \\
\hline S176 & $\mathrm{D}$ & O77:H18 & \\
\hline S182 & $\mathrm{D}$ & $\mathrm{O} 1: \mathrm{H}-$ & \\
\hline S191 & B2 & O16:H- & \\
\hline S192 & B2 & O83:H7 & \\
\hline S242 & B2 & $\mathrm{O} 25: \mathrm{H} 4$ & + \\
\hline
\end{tabular}

${ }^{a}$ Lytic spectra of isolated phage $\mathrm{EC} 200^{\mathrm{PP}}$ against different $E$. coli strains representative of the ECOR collection and E. coli meningitis strains (S prefix) of different serotypes and phylogenetic groups as well as reference strains (CFT073, 536, and J96) and strain TN03 representative of clone O25b:H4-ST131 producing CTX-15.

${ }^{b}$ Blank, absence of phage plaques; +: presence of phage plaques. filter. The enriched phage suspension was plated on LB agar medium with E. coli S242. Plaques formed on the plates after $24 \mathrm{~h}$ of incubation at $37^{\circ} \mathrm{C}$. Single plaques were picked for phage purification and amplification. The phage were then stored at $4^{\circ} \mathrm{C}$ in a suspension in LB broth or physiological saline. Phage titers were determined by spreading diluted samples on a lawn of E. coli S242; after overnight incubation, plaques were counted, and their morphologies were assessed.

Determination of phage-resistant bacteria rate. A total of $10^{9}$ to $10^{2}$ CFU of S242 was plated on a LB agar, and then $1 \mathrm{ml}$ of concentrated phage suspension containing $10^{9}$ phage particles was poured over the surface. After incubation overnight at $37^{\circ} \mathrm{C}$, isolated colonies representing phageresistant bacteria were counted, and the rate of phage-resistant bacteria was calculated (37).

Adsorption rate, latent period, and phage burst size. One-step growth experiments were carried out according to previous descriptions (13) to determine first the adsorption rate and then the latent period and phage burst size. To determine the adsorption rate, samples were taken at different time intervals to analyze the free phage particles in the solutions. For latent period and phage burst size determinations, E. coli bacteria were mixed with phage solutions, and phage were allowed to adsorb for $15 \mathrm{~min}$. The mixture was subjected to centrifugation immediately at 5,000 rpm for $10 \mathrm{~min}$ to remove free phage particles. The pellet was resuspended in fresh $\mathrm{LB}$ medium, and the culture was continuously incubated at $37^{\circ} \mathrm{C}$. Samples were taken at 3-min intervals, and phage titers were determined. These results permitted us to calculate the number of phage produced per bacteria (burst size, [(phage titer at the plateau phase) - (phage titer at the latent phase)]/number of infective centers) and the latent period.

Determination of the MOI. Serial dilutions of bacteriophage stock solution $\left(10^{7}\right.$ to $\left.1 \mathrm{PFU} / \mathrm{ml}\right)$ were mixed with the same amount of $E$. coli cells $\left(10^{8} \mathrm{CFU} / \mathrm{ml}\right)$. The multiplicity of infection (MOI) was calculated by determining the ratio of phage titer to the number of cells per ml. After 4 $\mathrm{h}$ of incubation at $37^{\circ} \mathrm{C}$, bacteriophage titers were determined and compared.

pH and thermal stability tests. $\mathrm{pH}$ stability and thermal stability tests were carried out as previously described $(9,13)$. Briefly, suspensions of $10^{9}$ $\mathrm{PFU}$ phage/ $\mathrm{ml}$ in LB medium were incubated at different $\mathrm{pH}$ and temperatures, and samples were taken at intervals for assay of surviving PFU.

Restriction fragment analysis of genomic DNA. Phage were precipitated from culture supernatant with $10 \%$ polyethylene glycol (6000) and 1 $\mathrm{M}$ sodium chloride and concentrated by centrifugation at $9,000 \times g$ for 2 $\mathrm{h}$ at $4^{\circ} \mathrm{C}$ and resuspension in phage buffer $(10 \mathrm{mM} \mathrm{MgSO}, 10 \mathrm{mM}$ Tris [pH 7.6], and $1 \mathrm{mM}$ EDTA) (10, 41). Phage DNA was isolated by phenol extraction, followed by ethanol precipitation. Phage DNA (300 ng) was digested with the endonucleases HindIII and PvuII as described by the manufacturer (New England BioLabs), and the fragments were separated and visualized in a $0.7 \%$ agarose gel as described previously.

Host range determination. Ability of phage to infect 68 E. coli clinical isolates was tested. A total of $10^{9}$ cells were mixed with melted agar, and this mixture was poured on solid agar to make double-layer agar plates. After solidification, $2 \times 10^{6} \mathrm{PFU}$ of bacteriophage stock suspensions was spotted on plates carrying each bacterial strain. After adsorption of the spots, the plates were inverted and incubated for $24 \mathrm{~h}$ at $37^{\circ} \mathrm{C}$ before the degree of lysis was scored $(37,46)$.

Endotoxin purification of phage before animal injection. Phage were purified from endotoxins using a commercially available kit (EndoTrapH Blue; Cambrex BioScience, Verviers, Belgium), according to the instructions of the manufacturer and as previously used by Merabishvili et al. for human application (32). The titer of phage in sterile physiological water was adjusted to $2 \times 10^{9} \mathrm{PFU} / \mathrm{ml}$ for animal injections.

Phage stability in different media. Stability assays were conducted by titrating phage at intervals during incubation in vitro at different temperatures and $\mathrm{pH}$ and ex vivo in rat serum, urine, and EDTA-treated blood and in human serum and urine. When necessary, serum was heated at $56^{\circ} \mathrm{C}$ for $30 \mathrm{~min}$ to inactivate complement. Human sera from 20 consenting healthy donors were obtained after approval from the institutional 
review board of Etablissement Français du Sang. Urine was from a healthy human volunteer (female, 30 years of age).

Pharmacokinetics. A total of $10^{7}$ PFU of phage was injected into 15 animals at day 5 , intraperitoneally (i.p.) or subcutaneously (s.c.) in the lower back, using a Microfine syringe $(0.3 \mathrm{ml}, 30$-gauge; Becton Dickinson). Groups of five animals were sacrificed at 2, 6, and $24 \mathrm{~h}$ after injection. EDTA-treated blood $(100 \mu \mathrm{l})$, cerebrospinal fluid (CSF; $10 \mu \mathrm{l})$, urine (50 $\mu \mathrm{l})$, spleen, kidney, and half-brain specimens were sampled. To evaluate the impact of contamination by red cells, all CSF samples were examined by microscopy for red cell contamination as previously described (22). Spleen, kidney, and half-brains were weighed and then crushed into 500 $\mu l$ of physiological saline. At 2 and $6 \mathrm{~h}$ postinjection, samples were kept at $4^{\circ} \mathrm{C}$ for analysis in parallel with 24 -h samples.

Sepsis models. All experiments and animal housing procedures complied with University Paris Diderot guidelines and were approved by the institutional review board (number 2011-14/676-0032). Four-day-old Sprague Dawley rat pups (Charles River, France) were received with mothers. For sepsis induction, inocula of S 242 in physiological saline were injected i.p. into rat pups at day 5. S242 inocula were prepared by overnight growth in brain heart infusion broth at $37^{\circ} \mathrm{C}$. After centrifugation, cells were resuspended in physiological saline, and the optical density at $600 \mathrm{~nm}\left(\mathrm{OD}_{600}\right)$ was adjusted to 1.3 , corresponding to $2 \times 10^{8} \mathrm{CFU} / \mathrm{ml}$. Suspensions were serially diluted to obtain correct inocula and for enumeration. To evaluate bacteremia, $5 \mu \mathrm{l}$ of blood was obtained by tail incision at 7, 24, and $48 \mathrm{~h}$ and diluted in $200 \mu \mathrm{l}$ of physiological saline and after 5 days by intracardiac puncture using EDTA. Quantitative cultures were obtained by sample serial dilution. To assess S242 meningeal invasion, CSF was obtained by cisterna magna puncture from animals anesthetized with isoflurane (Abbott).

Meningitis model by intrathecal injection. Meningitis by intrathecal inoculation via the cisterna magna was induced as previously described (38); $10 \mu$ l of different S242 inocula was injected into anesthetized pups using a Microfine syringe.

Experimental treatment by phage. According to the infection model under study, phage were administered by i.p. or s.c. route at different times postinfection, taking care to separate the sites of phage administration and bacterial inoculation. The bacteremia and sterility of CSF were evaluated at intervals ( $24 \mathrm{~h}, 48 \mathrm{~h}$, and 5 days) as described above. Phage counts in treated pups were performed as indicated above, at $24 \mathrm{~h}$ and 5 days in blood and CSF and at 5 days in crushed spleen.

Electron microscopy. Electron micrographs were taken with a transmission electron microscope (Philips CM10).

Statistical analysis. Data are given as means \pm standard errors. Significant differences in survival rates were determined among treatment groups by a log rank test (GraphPad Prism, version 4.00). Phage survival differences in different media were evaluated through two-way analysis of variance (ANOVA).

\section{RESULTS}

S242 belongs to the widespread $E$. coli clone O25:H4-ST131 that produces CTX-M-15. Phenotyping and molecular characterization indicated that $\mathrm{S} 242$ belongs to serotype O25:H4 with a positive PCR for O25b (14). It belongs to ST131 in the Achtmann multilocus sequence typing (MLST) scheme, and tests for all the genes sought were negative except iucA (aerobactin), fyuA (yersiniabactin), hra or hek (adhesion), and sat (secreted auto-transporter toxin). These results showed that $\mathrm{S} 242$ belongs to the E. coli clone O25b:H4-ST131 that produces CTX-M-15 $(14,35)$.

Characterization of a bacteriophage with therapeutic potential. Three phages active against S242 were isolated from environmental samples and purified. One, EC200 ${ }^{\mathrm{PP}}$, was found in preliminary experiments to be more stable in vitro, and this was chosen for the study and further characterization. Electron microscopy revealed a virion of $200 \mathrm{~nm}$ with an icosahedral head and a short

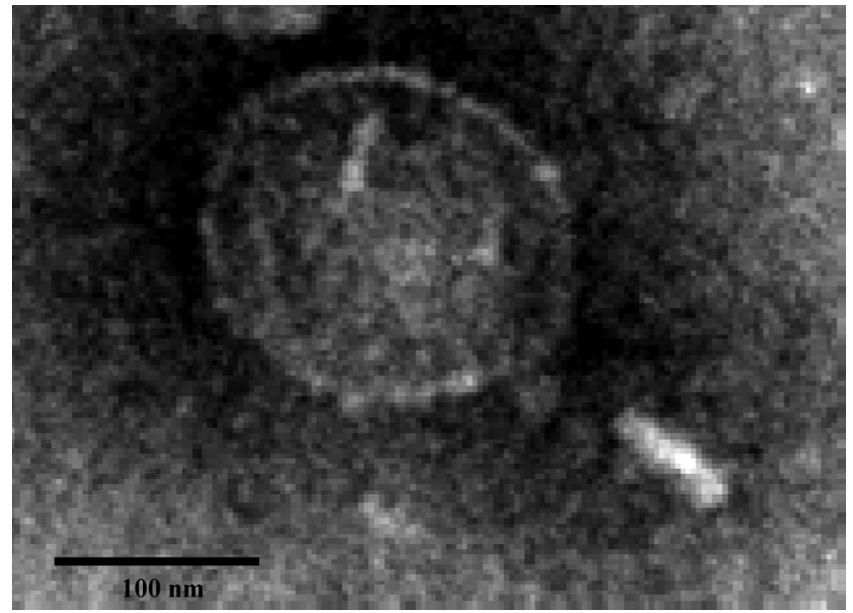

FIG 1 Transmission electron micrograph of a particle (size, $200 \mathrm{~nm}$ ) of bacteriophage $\mathrm{EC} 200^{\mathrm{PP}}$, a member of the Podoviridae family. Magnification, $\times 48,000$.

tail of $100 \mathrm{~nm}$, indicating that this phage probably belongs to the Podoviridae family (Fig. 1). Genome size was estimated by restriction endonuclease digestion to be 36 to $40 \mathrm{kbp}$.

EC200 ${ }^{\mathrm{PP}}$ formed plaques on 7 of 63 E. coli strains tested (Table 1), notably TN03. Therefore, EC200 ${ }^{\mathrm{PP}}$ has a narrow spectrum and is potentially active against the CTX-M-15-producing O25b:H4ST131 E. coli clonal group. The fraction of S242 cells resistant to $\mathrm{EC} 200^{\mathrm{PP}}$ was $7 \times 10^{-6}$. The main in vitro characteristics of $\mathrm{EC} 200^{\mathrm{PP}}$ against S242 (Fig. 2A and B) were an adsorption time of $20 \mathrm{~min}$, a 25 -min latent period, a burst size estimated to 10 , and an MOI of $10^{-3}$ giving the highest phage progeny yield.

Stability of EC200 ${ }^{\mathrm{PP}}$. Storage and body temperature stability are two important parameters in the therapeutic application of phage (Fig. 2C). After $24 \mathrm{~h}$ and 5 days at $37^{\circ} \mathrm{C}$ in saline, the titer had fallen by 1 and 2 orders of magnitude, respectively. Furthermore, EC200 ${ }^{\mathrm{PP}}$ was relatively sensitive to acidic $\mathrm{pH}$ (Fig. $2 \mathrm{D})$ but was stable for 1 month at room temperature $\left(20^{\circ} \mathrm{C}\right)$ and $\mathrm{pH} 6.0$ to 7.4 .

EC200 ${ }^{\mathrm{PP}}$ was stable in rat pup blood containing EDTA (anticoagulant used to sample blood) and in serum for at least $24 \mathrm{~h}$ (Fig. 3A). In contrast, in human serum the free-phage titer fell by 2 to 3 logs in $2 \mathrm{~h}$ and then remained stable, indicating a partial inhibitory activity of human serum. The same result was obtained with three separate human sera, rendering unlikely the presence of a phage-specific antibody in the serum pool (Fig. 3B). Neutralization was not observed in heated human serum, suggesting that complement is involved in the serum inhibitory effect. To determine whether the lack of phage neutralizing effect of rat pup serum was related to animal age and depletion in complement activity (28), we repeated the stability test using adult rat serum; no difference was observed between adult and rat pups. Finally, the inhibitory effect of serum was not specific to EC200 ${ }^{\mathrm{PP}}$ as the same partial neutralizing effect was observed with T4 phage (data not shown). In rat, as well as in human urine, $\mathrm{EC} 200^{\mathrm{PP}}$ appeared stable during $24 \mathrm{~h}$ at $37^{\circ} \mathrm{C}$ (Fig. $3 \mathrm{~A}$ ).

Innocuity and pharmacokinetics of $\mathbf{E C 2 0 0}{ }^{\mathrm{PP}}$. We examined innocuity and pharmacokinetics of $\mathrm{EC} 200^{\mathrm{PP}}$ introduced by i.p. and s.c. routes in uninfected animals. For the innocuity test, 10 animals received purification buffer without phage, 10 received 
A

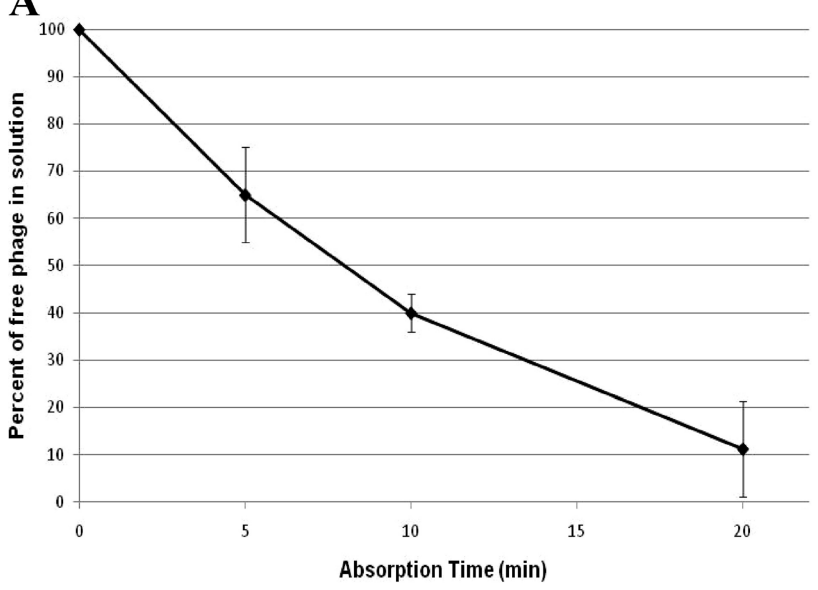

C

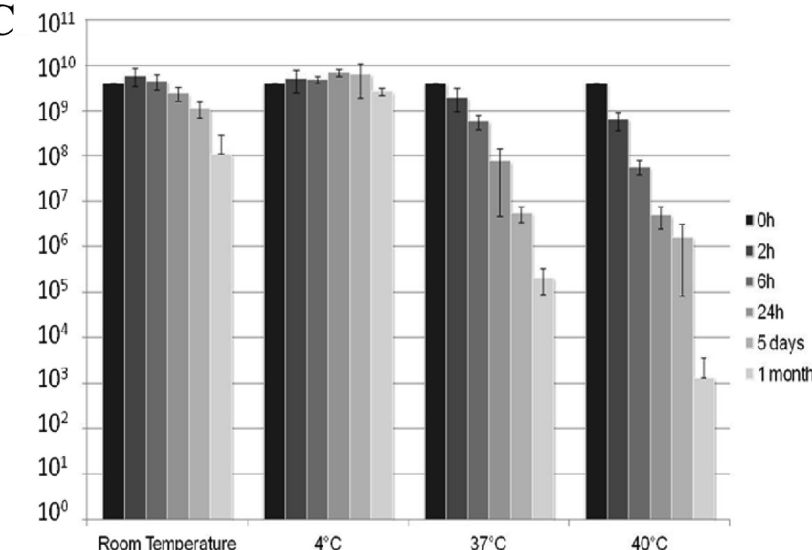

B

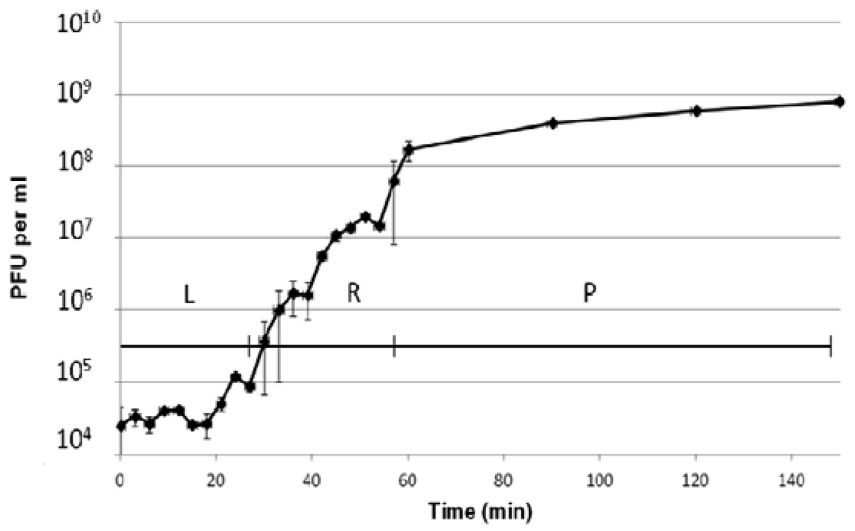

D

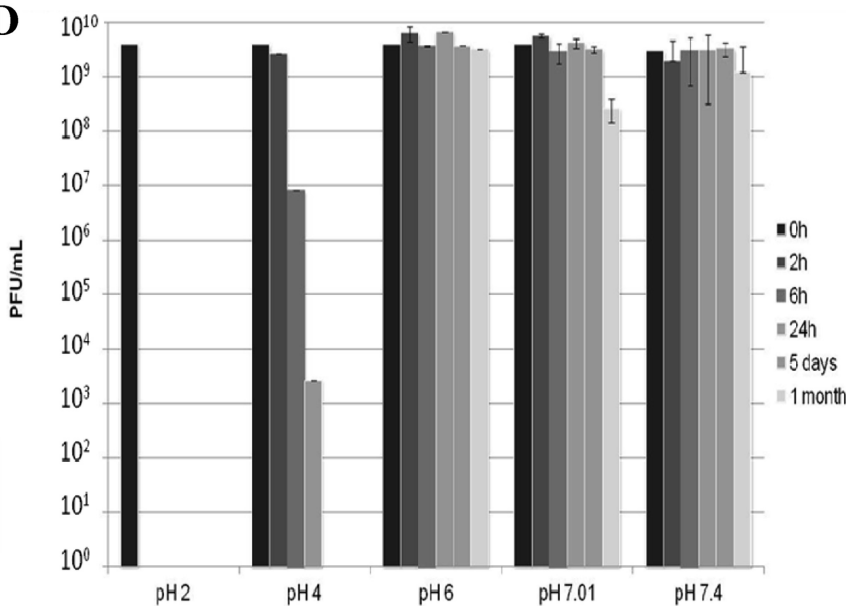

FIG 2 In vitro characterization of phage $\mathrm{EC} 200^{\mathrm{PP}}$ comprising an adsorption rate test (A), single-step growth experiment where latent time and burst size of phage $\mathrm{EC} 200^{\mathrm{PP}}$ were inferred from the curve with a triphasic pattern ( $\mathrm{L}$, latent phase; $\mathrm{R}$, rise phase; $\mathrm{P}$, plateau phase) $(\mathrm{B})$, thermal stability test $(\mathrm{C})$, and $\mathrm{pH}$ stability $(\mathrm{D})$.
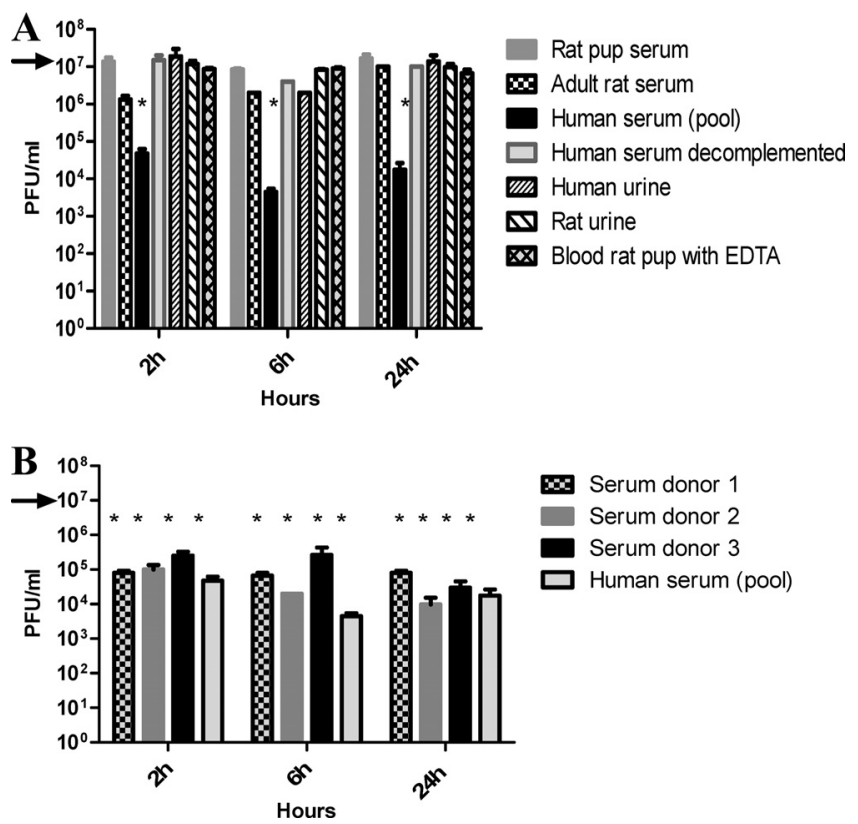

FIG 3 Stability of EC200 ${ }^{\mathrm{PP}}$ inoculated at $10^{7} \mathrm{PFU}$ (black arrow) in different media (A) and in sera of different donors (B) during $24 \mathrm{~h}\left({ }^{*}, P<0.001\right.$ versus initial inoculum).
$10^{8} \mathrm{PFU}$ of EC200 ${ }^{\mathrm{PP}}$ in saline, and 10 received saline. No sign of toxicity was observed, and weight gain averaged $11 \mathrm{~g}$ in 5 days for all groups. The i.p. pharmacokinetics assay showed a high concentration of EC200 $0^{\mathrm{PP}}$ in blood at $2 \mathrm{~h}\left(10^{7} \mathrm{PFU} / \mathrm{ml}\right)$; the phage were still detectable $\left(10^{3} \mathrm{PFU} / \mathrm{ml}\right)$ at $24 \mathrm{~h}$. In spleen and kidney, $\mathrm{EC} 200^{\mathrm{PP}}$ concentrations were higher than in blood and relatively stable, suggesting trapping by each organ (Fig. 4A). The blood/ tissue ratio in the brain extract was estimated to be 0.1 to 0.15 (39). Therefore, most phage detected in brain samples at 2 and $6 \mathrm{~h}$ presumably originated from blood. However, at $24 \mathrm{~h}$ the same phage concentration was found in brain and blood, implying that phage cross the blood-brain barrier (BBB). Unfortunately, the very low phage concentration in CSF meant that even minimal contamination of CSF by blood prevented us from drawing conclusions about phage passage through the blood-CSF barrier (BCB).

After s.c. administration phage concentration in blood was low and delayed compared to i.p. injection, with a peak at $6 \mathrm{~h}$ postinjection $\left(10^{5} \mathrm{PFU} / \mathrm{ml}\right)$, although phage were still detectable at $24 \mathrm{~h}$. High concentrations of phage were observed in spleen and kidney. We could not determine whether phage crossed the $\mathrm{BBB}$ or $\mathrm{BCB}$ after s.c. injection (Fig. 4B) because of the low level of phage detected and possible blood contamination. Finally, the passage of 

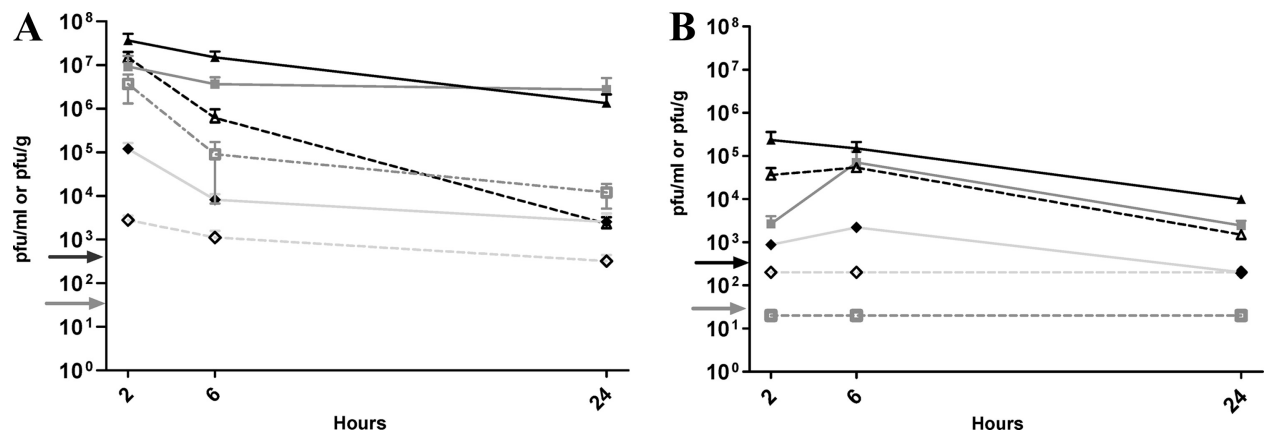

FIG 4 Pharmacokinetic study of EC200 ${ }^{\mathrm{PP}}$ after intraperitoneal injection (A) or subcutaneous injection (B) of $10^{8} \mathrm{PFU}$ in rat pups. Representation of mean $(n=$ 3 to 5) PFU/ml or PFU/g and standard error of the mean (SEM) in different organs or biologic fluids at 2, 6 and $24 \mathrm{~h}: \boldsymbol{\Lambda}$, spleen; $\bullet$, brain; $\boldsymbol{\square}$, kidney; $\triangle$, blood; $\diamond$, CSF; and $\square$, urine. Detection thresholds: blood and urine (gray arrow) 20 PFU/ml; spleen, kidney, brain, and CSF (black arrow) (200 PFU/ml or/g).

phage into urine was highly variable after i.p. administration as large differences were observed between individuals, and no phage were detected in urine after s.c. administration (Fig. 4A and B).

Sepsis model and treatment. The virulence of S242 in rat pups was evaluated by i.p. injection of $10^{3}$ to $10^{6} \mathrm{CFU}$. An inoculum of $10^{4} \mathrm{CFU}$ was chosen as it produced bacteremia of $3.08 \pm 0.4 \mathrm{log}$ $\mathrm{CFU} / \mathrm{ml}$ at $7 \mathrm{~h}, 5.7 \pm 0.03 \log \mathrm{CFU} / \mathrm{ml}$ associated with peritonitis at $24 \mathrm{~h}$, and finally death of all animals between 36 and $48 \mathrm{~h}$. At 24 $\mathrm{h}$ postinfection meningitis was observed in only $15 \%(2 / 13)$ of the pups.

Two groups of 10 rat pups were infected with $10^{4}$ CFU of S242 and treated at $7 \mathrm{~h}$ or $24 \mathrm{~h}$ postinfection by s.c. injection of $10^{8} \mathrm{PFU}$ of EC200 ${ }^{\mathrm{PP}}$ (Fig. 5A). All rats survived when injection was at $7 \mathrm{~h}$, and blood cultures were sterile as soon as $24 \mathrm{~h}$ postinfection. When injection was delayed to $24 \mathrm{~h}$, half the rats survived until day 5 , with negative blood cultures. In the group treated at $24 \mathrm{~h}$ postinfection, atypical colonies with rough morphology were observed upon plating blood samples taken $48 \mathrm{~h}$ after infection $(5 \pm 0.3 \mathrm{log}$ $\mathrm{CFU} / \mathrm{ml})$. These colonies were resistant to $\mathrm{EC} 200^{\mathrm{PP}}$. One rough strain, named $\mathrm{O} 4-\mathrm{EC} 200^{\mathrm{PP}} \mathrm{R}$, was further characterized.

Characterization of mutant $\mathrm{O} 4-\mathrm{EC} 200^{\mathrm{PP}} \mathrm{R}$. Growth rates of S242 and O4-EC200 ${ }^{\mathrm{PP}} \mathrm{R}$ in LB medium were identical (see Fig. S1 in the supplemental material), and biochemical properties, antibiotic susceptibility, and virulence factor expression were identical for mutant and parent strains (data not shown). However, whereas S242 survived and grew in human serum, O4-EC200 ${ }^{\mathrm{PP}} \mathrm{R}$ was very serum sensitive; a 2-h exposure to serum reduced viability of the phage-resistant strain by at least 5 logs (see Fig. S2). To explore in vivo properties of $\mathrm{O} 4-\mathrm{EC} 200{ }^{\mathrm{PP}} \mathrm{R}$, we examined its behavior in a sepsis model. After i.p. injection of $10^{4} \mathrm{CFU}$, we observed sepsis in 7/10 animals at day 1 (4.3 $\pm 0.9 \log \mathrm{CFU} / \mathrm{ml}$ ) (Fig. 5B). Animal survival at day 5 was $100 \%$, with all blood cultures being negative. These results indicated that the $\mathrm{O} 4-\mathrm{EC} 200^{\mathrm{PP}} \mathrm{R}$ strain selected after EC $200^{\mathrm{PP}}$ treatment had a dramatically attenuated virulence associated with a pronounced susceptibility to serum. Additionally, a pool of rough colonies was tested as O4$\mathrm{EC} 200{ }^{\mathrm{PP}} \mathrm{R}$ had been, and similar results were obtained, indicating that attenuated virulence was not unique to $\mathrm{O} 4-\mathrm{EC} 200^{\mathrm{PP}} \mathrm{R}$ (data not shown).

Meningitis model and treatment. Since the sepsis model with $10^{4} \mathrm{CFU}$ injected by the i.p. route induced meningitis in only $15 \%$ of rat pups, an intrathecal model was chosen for assessment of meningitis treatment to use a minimum number of animals. Two hundred CFU of S242 was injected in the cisterna magna. Death ensued for $70 \%$ animals at $24 \mathrm{~h}$ and for all animals at $36 \mathrm{~h}$. At $24 \mathrm{~h}$, CSF samples of living animals yielded at least $10^{6} \mathrm{CFU} / \mathrm{ml}$. A group of 5 pups was treated with $10^{8} \mathrm{PFU}$ of EC200 ${ }^{\mathrm{PP}}$ by the i.p. route $1 \mathrm{~h}$ after infection. After $24 \mathrm{~h}$ all animals had sterile CSF and an average concentration of phage in CSF of $4.5 \pm 0.2 \log \mathrm{PFU} / \mathrm{ml}$. All animals survived to day 5 with no phage detected in CSF, blood, or spleen (Fig. 6A).

Treatment initiated $7 \mathrm{~h}$ postinfection allowed a survival of
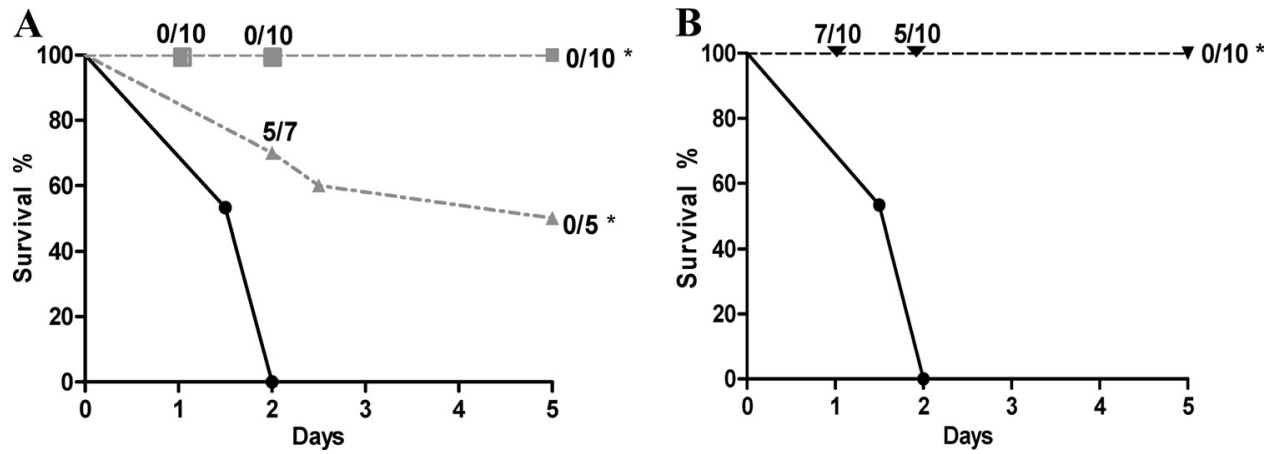

FIG 5 (A) Survival curves after intraperitoneal injection of $2 \times 10^{4} \mathrm{CFU}$ of $E$. coli S242 in rat pups without treatment $(\bullet ; n=30)$ or treated at $7 \mathrm{~h}(\mathbf{\square} ; n=10)$ or $24 \mathrm{~h}(\mathbf{\Delta} ; n=10)$ after infection by $10^{8} \mathrm{PFU}$ of EC200 ${ }^{\mathrm{PP}}$ subcutaneously administered $\left({ }^{*}, P<0.001\right.$ versus no treatment). Ratios on the figure indicate at different time points the rate of positive blood culture. (B) Survival curves after i.p. injection of $2 \times 10^{4} \mathrm{CFU}$ of E. coli S242( $\left.) ; n=30\right)$ or $2 \times 10^{4} \mathrm{CFU}$ of O4-EC200 ${ }^{\mathrm{PP}} \mathrm{R}(\boldsymbol{\nabla} ; n=10)$ in rat pups $\left({ }^{*}, P<0.001\right.$ versus $\left.\mathrm{S} 242\right)$. Ratios on the figure indicate at different time points the rate of positive blood culture. 

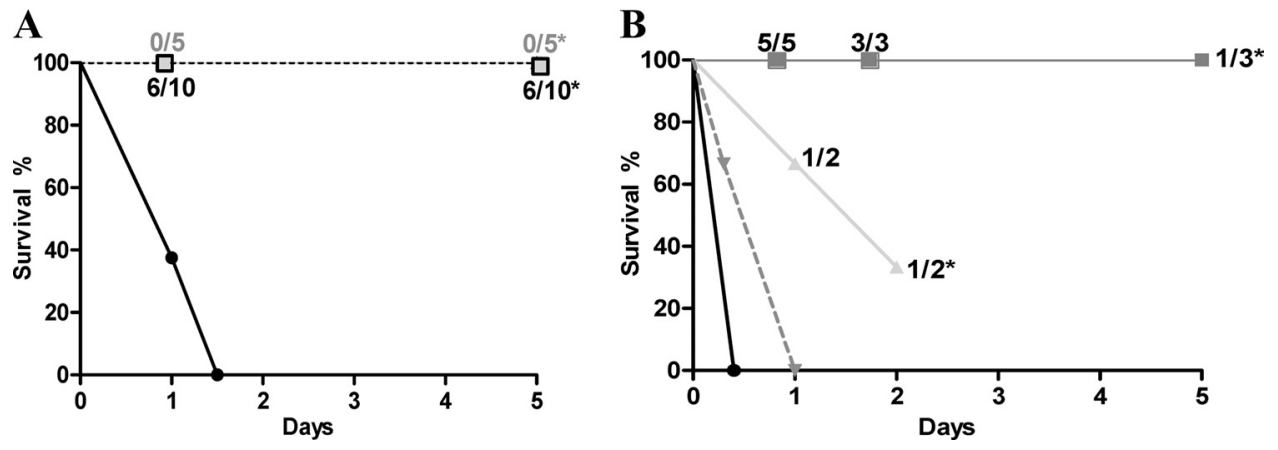

FIG 6 (A) Survival curves after intrathecal injection of $200 \mathrm{CFU}$ of S242 in rat pups without treatment $(\mathbf{O} ; n=10)$ or treated at $1 \mathrm{~h}(\mathbf{\square} ; n=5)$ or $7 \mathrm{~h}(\square ; n=$ 10) after infection by $10^{8} \mathrm{PFU}$ of EC200 ${ }^{\mathrm{PP}}$ by i.p. injection. Ratios on the figure indicate at different time points the rate of positive CSF cultures $\left({ }^{*}, P<0.001\right.$ versus no treatment). (B) Survival curves after intrathecal injection of $2 \times 10^{6} \mathrm{CFU}$ of S242 in rat pups without treatment $(\mathbf{O} ; n=10)$ or treated at $1 \mathrm{~h}(\mathbf{\square} ; n=$ 5), $2 \mathrm{~h}(\boldsymbol{\Lambda} ; n=3)$, or $4 \mathrm{~h}(\mathbf{\nabla} ; n=3)$ postinfection by $10^{8} \mathrm{PFU}$ of EC200 ${ }^{\mathrm{PP}}$ by i.p. injection. Ratios on the figure indicate at different time points the rate of positive CSF cultures ${ }^{*}, P<0.005$ versus no treatment).

$10 / 10$ animals at 5 days. However, 6/10 cultures from corresponding CSF samples were positive at days 1 and 5 (4.8 \pm 0.9 and $3.8 \pm$ $0.5 \log \mathrm{CFU} / \mathrm{ml}$, respectively). At day 5 , both rough and typical S242 colonies were observed. At day 1, CSF contained on average $5.3 \pm 0.8 \log \mathrm{PFU} / \mathrm{ml}$, whereas phage quantity in blood was equal or inferior to the detection threshold. No phage were found at day 5 in CSF, blood, or spleen.

In light of these encouraging results, we wondered whether phage therapy could be effective with a higher inoculum such as that observed during human meningitis (26). A total of $2 \times 10^{6}$ $\mathrm{CFU}$ was injected in pup cisterna magna. Without treatment, $100 \%$ of animals died in less than $12 \mathrm{~h}$ (Fig. 6B). At $1 \mathrm{~h}$ after infection $10^{8}$ PFU of EC200 ${ }^{\mathrm{PP}}$ was injected i.p. All animals were alive at day 5 . For all animals at $24 \mathrm{~h}$, CSF cultures were positive but without bacteremia. Phage concentration in CSF (5.8 \pm 0.3 $\log \mathrm{PFU} / \mathrm{ml})$ was 10 -fold higher than that in blood $(4.6 \pm 0.3 \log$ $\mathrm{PFU} / \mathrm{ml}$ ), demonstrating the capacity of phage to cross the $\mathrm{BCB}$ and grow within the bacteria. At $48 \mathrm{~h}$, all CSF samples were positive, but at day 5, two of three animals displayed sterile CSF; the third was positive. No CSF sample could be obtained from the two other animals. When treatments were delayed $2 \mathrm{~h}(n=3)$ and $4 \mathrm{~h}$ postinfection $(n=4)$, efficiency and survival rate declined dramatically (Fig. 6B).

\section{DISCUSSION}

In the last 5 years, significant increases in E. coli strains resistant to extended-spectrum cephalosporins have been observed in 14 of 33 European countries (www.ecdc.europa.eu). At present, carbapenems appear to be the last available treatment for severe infections caused by ESBL-producing E. coli. The recent emergence of carbapenemase in E. coli and the lack of new antibiotic discovery emphasize the need to develop alternatives. We have shown here, for the first time, that Podoviridae bacteriophage can cure sepsis and meningitis induced by an E. coli strain belonging to O25b:H4ST131 clone, which produces CTX-M-15 and is spread throughout the world.

Our phage $\mathrm{EC} 200^{\mathrm{PP}}$ displayed a potent lytic activity as well as stability within physiological ranges of temperature and $\mathrm{pH}$. To assess EC200 ${ }^{\mathrm{PP}}$ lytic activity in human tissues, we conducted ex vivo assays of phage in serum and urine. Our phage were stable in urine and moderately inactivated in human serum though not by serum of rat (or mouse) (data not shown). The neutralizing effect appeared to be related to complement activity. Specific antibodies, which phage are known to induce, are a potential alternative source of inhibitory activity $(8,43)$. However, the similar neutralizing effects of the sera of three donors and the pool strongly suggest that human innate immunity is mainly responsible for the partial inactivation. Very few studies have noted that mammalian serum is able to neutralize bacteriophage (42). Antibodies have been assumed to be responsible, but the exact source and mechanisms of neutralization have not been studied during the last 50 years. Our results thus suggest that human innate immunity might limit the efficacy of phage therapy in systemic experimental infection models. Similar results for phage T4 imply that this might be true of phage more generally. On the other hand, serum neutralization was rapid but incomplete, leaving $10^{4}$ to $10^{5}$ $\mathrm{PFU} / \mathrm{ml}$ after $24 \mathrm{~h}$ of incubation, and phage could replicate in the presence of their pathogenic bacterial host and so compensate for phage losses (45). Whether different phages have various abilities to resist human serum inactivation remains to be evaluated; we suggest that future assessments of experimental phage therapy should include this evaluation.

Pharmacokinetic properties of phage in experimental models using adult mice have been described previously (19, 31, 36, 40, 44) but, to our knowledge, they have never been studied in a neonatal murine model. Our data indicated that EC200 ${ }^{\mathrm{PP}}$ was partially retained by spleen and kidney, where phage concentrations were at any time as high or higher than in blood, especially after intraperitoneal injection, as in mouse models $(19,31,36)$. The basis of this trapping phenomenon remains to be determined (19). Of relevance to reduction of phage elimination by the host defense system, Merril et al. showed that serial passages in mice selected for phage that remain in the circulatory system (33).

Although our infection models did not involve the urinary tract, phage diffusion into urine was studied since $20 \%$ of neonatal meningitis cases are secondary to a pyelonephritis (21). Despite the high concentrations of phage observed in kidney, phage were present in urine after i.p. injection at a 1,000-fold lower concentration; no phage could be detected in urine after s.c. administration. Since we excluded the degradation of EC200 ${ }^{\mathrm{PP}}$ in pup urine, low diffusion into urine is the likely explanation. Nishikawa et al. (36) examined secretion of phage T4 into urine after i.p. injection in mice and observed a much lower count than in kidney. Such 
low concentrations were sufficient to treat animals with urinary tract infection, suggesting that a limited diffusion may be counterbalanced by phage growth in the inoculum bacteria. Finally, low brain concentrations of $\mathrm{EC} 200^{\mathrm{PP}}$ and nondetection in CSF suggest its low capacity to cross the BBB or BCF. Such pharmacokinetics have been described in mice $(36,40)$, but diffusion in CSF has not been reported before.

Using a severe model of sepsis, which leads to $100 \%$ lethality in less than $48 \mathrm{~h}$, we showed that phage $\mathrm{EC} 200^{\mathrm{PP}}$ administered in a single dose up to $7 \mathrm{~h}$ postinfection resulted in $100 \%$ survival. Even when the treatment was delayed by $24 \mathrm{~h}$ postinfection, $50 \%$ animal rescue was obtained. Smith et al., using a model of E. coli K1 septicemia, found only one natural phage, among 15 phages active in vitro, that cured $100 \%$ of animals at $8 \mathrm{~h}$ postinfection. However, when the treatment was delayed to $16 \mathrm{~h}$ postinfection, all animals died $(7,40)$. This underlines the remarkable in vivo activity of $\mathrm{EC} 200^{\mathrm{PP}}$. Moreover, in vivo activity of EC $200^{\mathrm{PP}}$ was not hampered by the selection of phage-resistant S242 since the mutants were avirulent. Reduced in vivo virulence without in vitro fitness cost has been reported previously for phage-resistant enterobacterial strains $(8,23)$, as in the present study (see Fig. S1 in the supplemental material). In our case, the high sensitivity to serum killing may explain the lack of virulence of the phage-resistant isolate.

$\mathrm{K} 1$ capsular antigen is known to be a major virulence factor involved in crossing the BCB (25). Yet 10 to $20 \%$ of E. coli meningitis strains, like S242, do not harbor this antigen (4). Although our strain was able to induce bacteremia levels compatible with $\mathrm{BCB}$ crossing (25), low rates of meningitis were observed. Consequently, we used a previously published intracisternal infection method (24). Others studies had evaluated phage therapy in experimental central nervous system infections by intracranial inoculation with $E$. coli $(1,17,40)$. This model does not match the usual site of $E$. coli infection since intracerebral, in contrast to CSF, infections are very rare in neonates (20). Although $\mathrm{EC} 200^{\mathrm{PP}}$ has a low propensity for crossing the $\mathrm{BCB}$, early administration after bacterial inoculation gave a major boost to survival, even when a high inoculum, such as that encountered in clinics, was used (30). Even if a low quantity of phage reaches the subarachnoidal space, it may be sufficient to infect bacteria, multiply, and finally sterilize CSF. The sterilization of CSF, as well as the higher concentration of phage in CSF than in animal blood treated at $1 \mathrm{~h}$ or $7 \mathrm{~h}$ after infection, strongly supports the notion that $\mathrm{EC} 200^{\mathrm{PP}}$ crosses the BCB.

Our work demonstrates the genuine potential of bacteriophage for treating sepsis and meningitis infections induced by the multidrug-resistant O25b:H4-ST131 E. coli. Further studies will aim to optimize this strategy through reduction of phage elimination by the host defense system and by enhancing barrier crossing.

\section{ACKNOWLEDGMENTS}

This work was supported in part by the Société Française de Pédiatrie.

We thank P. Lebon who performed the electronic microscopy study and G. Arlet for providing strain TN03. We thank Pascale Neveu and José Alvez, from the Subdivision Contrôle des Eaux, SATESE 75, Section d'assainissement de Paris, STEA, Mairie de Paris, Direction de la Propreté et de l'Eau, and the SIAAP, Direction du Développement et de la Prospective, Service Etudes et Méthodes, for providing environmental water samples.

\section{REFERENCES}

1. Barrow P, Lovell M, Berchieri A, Jr. 1998. Use of lytic bacteriophage for control of experimental Escherichia coli septicemia and meningitis in chickens and calves. Clin. Diagn. Lab. Immunol. 5:294-298.

2. Bidet P, et al. 2007. Combined multilocus sequence typing and o serogrouping distinguishes Escherichia coli subtypes associated with infant urosepsis and/or meningitis. J. Infect. Dis. 196:297-303.

3. Birgy A, et al. 2011. Early detection of colonization by VIM-1-producing Klebsiella pneumoniae and NDM-1-producing Escherichia coli in two children returning to France. J. Clin. Microbiol. 49:3085-3087.

4. Bonacorsi S, et al. 2003. Molecular analysis and experimental virulence of French and North American Escherichia coli neonatal meningitis isolates; identification of new virulent clone. J. Infect. Dis. 187:1895-1906.

5. Boyer-Mariotte S, et al. 2008. CTX-M-15-producing Escherichia coli in fatal neonatal meningitis: failure of empirical chemotherapy. J. Antimicrob. Chemother. 62:1472-1474.

6. Bruttin A, Brussow H. 2005. Human volunteers receiving Escherichia coli phage T4 orally: a safety test of phage therapy. Antimicrob. Agents Chemother. 49:2874-2878.

7. Bull JJ, Levin BR, DeRouin T, Walker N, Bloch CA. 2002. Dynamics of success and failure in phage and antibiotic therapy in experimental infections. BMC Microbiol. 2:35. doi:10.1186/1471-2180-2-35.

8. Capparelli R, et al. 2010. Bacteriophage therapy of Salmonella enterica: a fresh appraisal of bacteriophage therapy. J. Infect. Dis. 201:52-61.

9. Capra ML, Quiberoni A, Reinheimer J. 2006. Phages of Lactobacillus casei/paracasei: response to environmental factors and interaction with collection and commercial strains. J. Appl. Microbiol. 100:334-342.

10. Carey-Smith GV, Billington C, Cornelius AJ, Hudson JA, Heinemann JA. 2006. Isolation and characterization of bacteriophages infecting Salmonella spp. FEMS Microbiol. Lett. 258:182-186.

11. Carmody LA, et al. 2010. Efficacy of bacteriophage therapy in a model of Burkholderia cenocepacia pulmonary infection. J. Infect. Dis. 201:264271.

12. Chibani-Chennoufi S, et al. 2004. In vitro and in vivo bacteriolytic activities of Escherichia coli phages: implications for phage therapy. Antimicrob. Agents Chemother. 48:2558-2569.

13. Chow JJ, Batt CA, Sinskey AJ. 1988. Characterization of Lactobacillus bulgaricus bacteriophage ch2. Appl. Environ. Microbiol. 54:1138-1142.

14. Clermont O, et al. 2008. The CTX-M-15-producing Escherichia coli diffusing clone belongs to a highly virulent B2 phylogenetic subgroup. J. Antimicrob. Chemother. 61:1024-1028.

15. Debarbieux L, et al. 2010. Bacteriophages can treat and prevent Pseudomonas aeruginosa lung infections. J. Infect. Dis. 201:1096-1104.

16. Dubois D, et al. 2009. CTX-M beta-lactamase production and virulence of Escherichia coli K1. Emerg. Infect. Dis. 15:1988-1990.

17. Dubos RJ, Straus JH, Pierce C. 1943. The multiplication of bacteriophage in vivo and its protective effect against an experimental infection with Shigella Dysenteriae. J. Exp. Med. 78:161-168.

18. Gaschignard J, et al. 2011. Neonatal bacterial meningitis: 444 cases in 7 years. Pediatr. Infect. Dis. J. 30:212-217.

19. Geier MR, Trigg ME, Merril CR. 1973. Fate of bacteriophage lambda in non-immune germ-free mice. Nature 246:221-223.

20. Houdouin V, et al. 2008. Association between mortality of Escherichia col meningitis in young infants and non-virulent clonal groups of strains. Clin. Microbiol. Infect. 14:685-690.

21. Houdouin V, et al. 2008. Clinical outcome and bacterial characteristics of 99 Escherichia coli meningitis in young infants. Arch. Pediatr. 15(Suppl 3):S138-S147.

22. Houdouin V, et al. 2002. A uropathogenicity island contributes to the pathogenicity of Escherichia coli strains that cause neonatal meningitis. Infect. Immun. 70:5865-5869.

23. Hung CH, Kuo CF, Wang CH, Wu CM, Tsao N. 2011. Experimental phage therapy in treating Klebsiella pneumoniae-mediated liver abscesses and bacteremia in mice. Antimicrob. Agents Chemother. 55:1358-1365.

24. Kim KS. 1985. Comparison of cefotaxime, imipenem-cilastatin, ampicillin-gentamicin, and ampicillin-chloramphenicol in the treatment of experimental Escherichia coli bacteremia and meningitis. Antimicrob. Agents Chemother. 28:433-436.

25. Kim KS, et al. 1992. The K1 capsule is the critical determinant in the development of Escherichia coli meningitis in the rat. J. Clin. Invest. 90: 897-905.

26. Kim KS, Manocchio M, Bayer AS. 1984. Efficacy of cefotaxime and 
latamoxef for Escherichia coli bacteremia and meningitis in newborn rats. Chemotherapy 30:262-269.

27. Kutter E, et al. 2010. Phage therapy in clinical practice: treatment of human infections. Curr. Pharm. Biotechnol. 11:69-86.

28. Lassiter HA, Watson SW, Seifring ML, Tanner JE. 1992. Complement factor 9 deficiency in serum of human neonates. J. Infect. Dis. 166:53-57.

29. Mahjoub-Messai F, et al. 2011. Escherichia coli isolates causing bacteremia via gut translocation and urinary tract infection in young infants exhibit different virulence genotypes. J. Infect. Dis. 203:1844-1849.

30. Mariani-Kurkdjian P, et al. 1999. Bacterial concentration in the cerebrospinal fluid in childhood meningitis. Presse Med. 28:1227-1230.

31. McVay CS, Velasquez M, Fralick JA. 2007. Phage therapy of Pseudomonas aeruginosa infection in a mouse burn wound model. Antimicrob. Agents Chemother. 51:1934-1938.

32. Merabishvili M, et al. 2009. Quality-controlled small-scale production of a well-defined bacteriophage cocktail for use in human clinical trials. PLoS One 4:e4944. doi:10.1371/journal.pone.0004944.

33. Merril CR, et al. 1996. Long-circulating bacteriophage as antibacterial agents. Proc. Natl. Acad. Sci. U. S. A. 93:3188-3192.

34. Moissenet D, et al. 2010. Meningitis caused by Escherichia coli producing TEM-52 extended-spectrum beta-lactamase within an extensive outbreak in a neonatal ward: epidemiological investigation and characterization of the strain. J. Clin. Microbiol. 48:2459-2463.

35. Nicolas-Chanoine MH, et al. 2008. Intercontinental emergence of Escherichia coli clone O25:H4-ST131 producing CTX-M-15. J. Antimicrob. Chemother. 61:273-281.

36. Nishikawa $\mathrm{H}$, et al. 2008. T-even-related bacteriophages as candidates for treatment of Escherichia coli urinary tract infections. Arch. Virol. 153:507-515.
37. Postic B, Finland M. 1961. Observations on bacteriophage typing of Pseudomonas aeruginosa. J. Clin. Invest. 40:2064-2075.

38. Scheld M. 1986. Experimental animal models of bacterial meningitis, $p$ 139-186. In Zak O, Sands MA (ed), Experimental models in antimicrobial chemotherapy, vol. 1. Academic Press, New York, NY.

39. Sherwood L. 2006. Blood vessel and arterial tension, p 286. In Boeck D (ed), Human physiology, 2nd ed. Thomson Brooks/Cole, Belmont, CA

40. Smith HW, Huggins MB. 1982. Successful treatment of experimental Escherichia coli infections in mice using phage: its general superiority over antibiotics. J. Gen. Microbiol. 128:307-318.

41. Stenholm AR, Dalsgaard I, Middelboe M. 2008. Isolation and characterization of bacteriophages infecting the fish pathogen Flavobacterium psychrophilum. Appl. Environ. Microbiol. 74:4070-4078.

42. Toussaint AJ, Muschel LH. 1959. Neutralization of bacteriophage by normal serum. Nature 183:1825-1827.

43. Wang J, et al. 2006. Therapeutic effectiveness of bacteriophages in the rescue of mice with extended spectrum beta-lactamase-producing Escherichia coli bacteremia. Int. J. Mol. Med. 17:347-355.

44. Watanabe R, et al. 2007. Efficacy of bacteriophage therapy against gutderived sepsis caused by Pseudomonas aeruginosa in mice. Antimicrob. Agents Chemother. 51:446-452.

45. Weber-Dabrowska B, Mulczyk M, Gorski A. 2003. Bacteriophages as an efficient therapy for antibiotic-resistant septicemia in man. Transplant. Proc. 35:1385-1386.

46. Yang H, Liang L, Lin S, Jia S. 2010. Isolation and characterization of a virulent bacteriophage $\mathrm{AB} 1$ of Acinetobacter baumannii. BMC Microbiol. 10:131. doi:10.1186/1471-2180-10-131. 